\title{
miR-34c plays a role of tumor suppressor in HEC-1-B cells by targeting E2F3 protein
}

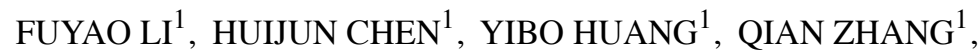 \\ JISEN XUE ${ }^{1}$, ZAN LIU $^{2}$ and FEIYUN ZHENG ${ }^{1}$ \\ ${ }^{1}$ Department of Gynecology, The First Affiliated Hospital of Wenzhou Medical University, Wenzhou, Zhejiang 325000; \\ ${ }^{2}$ Department of General Surgery, Zhuzhou Kind Hospital, Zhuzhou, Hunan 412000, P.R. China
}

Received December 2, 2014; Accepted March 12, 2015

DOI: $10.3892 /$ or.2015.3894

\begin{abstract}
Endometrial carcinoma (EC) is a common malignancy of the female genital tract with a poor prognosis. It has been reported that miR-34c is significantly reduced in $\mathrm{EC}$, but research concerning its function in EC is rare. In the present study, the expression of miR-34c was upregulated in the EC cell line, HEC-1-B, by transfecting the cells with hsamiR-34c-5p mimics. Then, after determining the transfection efficiency by RT-qPCR, we analyzed the effects of miR-34c on the HEC-1-B cells. We found that overexpression of miR-34c significantly inhibited cell proliferation, colony formation, migration and invasion and induced cell cycle arrest and apoptosis. Finally, western blot analysis demonstrated that the expression of E2F3 was reduced after upregulation of the expression of miR-34c in the HEC-1-B cells, and the effects of miR-34c are likely associated with the reduction in E2F3 protein. In conclusion, our study demonstrated that miR-34c plays a role of tumor suppressor in HEC-1-B cells, and E2F3 protein may be a target of miR-34c.
\end{abstract}

\section{Introduction}

Endometrial carcinoma (EC) is one of the most common malignancies of the female genital tract. Mortality rates from EC are increasing in many countries and this may be attributed to an increased rate of advanced stage cancers and high-risk histologies (1). Surgery is currently the major treatment for EC, yet it is critically important to develop new therapeutic strategies for EC. Research of the molecular mechanisms of EC may help to identify new diagnostic and therapeutic targets.

MicroRNAs (miRNAs) are 18-24 nucleotide non-coding RNAs which play an important role in regulating gene expression by cleaving or translational repression of mRNAs (2).

Correspondence to: Professor Feiyun Zheng, Department of Gynecology, The First Affiliated Hospital of Wenzhou Medical University, Wenzhou, Zhejiang 325000, P.R. China

E-mail: zfy5710@163.com

Key words: microRNA, miR-34c, proliferation, apoptosis, cell cycle arrest, invasion, E2F3, endometrial carcinoma
Recent studies have demonstrated the dysregulation of specific miRNAs in different types of tumors, including stomach, lung, breast, ovarian and cervical cancer and leukemia (3-5). These miRNAs may act as tumor suppressors or oncogenes by regulating processes such as cell proliferation, apoptosis, metastasis and invasion (5-8), and our previous research demonstrated that miR-449a is a suppressor of EC (9).

The miR-34 family consists of miR-34a (5'-UGGCAG UGUCUUAGCUGGUUGU-3'), miR-34b (5'-CAAUCACUA ACUCCACUGCCAU-3') and miR-34c (5'-AGGCAGUGU AGUUAGCUGAUUGC-3'). Numerous studies have shown the dysregulation of miR-34 in various types of cancers, including hepatocellular, mesothelial and colon cancer, melanomas, neuroblastomas and leukemia (10-12). Yet, little research has been conducted in endometrial cancer.

E2F3 is a member of the E2F family, and is essential for tumor growth by regulating cell proliferation and apoptosis $(13,14)$. Whether E2F3 acts on endometrial cancer cells remains unclear.

In the present study, we investigated the relationship between miR-34c and EC. It has been reported that miR-34c is significantly reduced in EC $(15,16)$, and numerous studies have shown that decreased expression of miR-34c in cancer cells correlates with aberrant DNA methylation $(17,18)$. To further study the function of $\mathrm{miR}-34 \mathrm{c}$ in $\mathrm{EC}$, we upregulated the expression of miR-34c in the EC cell line, HEC-1-B, and then sought to identify the effect of miR-34c on cell proliferation, colony formation, cell cycle arrest, apoptosis, migration and invasion. Finally, we determined the expression of E2F3 in the HEC-1-B cells using western blot analysis.

\section{Materials and methods}

Cell line and culture. EC cell line (HEC-1-B) was obtained from the Shanghai Institute of Cell Biology (Shanghai, China). The cells were maintained in Dulbecco's modified Eagle's medium (DMEM) supplemented with $10 \%$ fetal bovine serum (FBS) (both from Gibco), and incubated under a condition of a humidified atmosphere of $5 \% \mathrm{CO}_{2}$ and $95 \%$ air at $37^{\circ} \mathrm{C}$.

Cell transfection. We purchased hsa-miR-34c-5p mimics and a negative control (NC) from GenePharma (Shanghai, China). The sequence of hsa-miR-34c-5p mimics was 5'-AGGCAGU 
GUAGUUAGCUGAUUGC-3' and the sequence of NC was 5'-UUCUCCGAACGUGUCACGUTT-3'. One day before transfection, HEC-1-B cells were seeded in 96-well plates at $2.5 \times 10^{3}$ or $2 \times 10^{5}$ cells/well in 6-well plates in growth medium (DMEM supplemented with 10\% FBS) without antibiotics, such that they were $30-50 \%$ confluent at the time of transfection. On the following day, the cells were transfected with hsa-miR-34c-5p mimics or NC at a final concentration of $50 \mathrm{nmol} / \mathrm{l}$ using Lipofectamine 2000 transfection reagent (Invitrogen) according to the manufacturer's instructions. There were three groups: the miR-34c group, the NC group, and the untransfected group.

$R N A$ isolation and $R T-q P C R$. Reverse transcription quantitative PCR (RT-qPCR) was applied to ensure that the HEC-1-B cells were successfully transfected. Forty-eight hours after transfection, total RNA was isolated from the HEC-1-B cells with TRIzol reagent (Invitrogen) according to the manufacturer's instructions. Reverse transcription PCR (RT-PCR) and real-time PCR (qPCR) were performed according to the manufacturer's instructions. Briefly, miRNAs (contained in $500 \mathrm{ng}$ total RNA each group) were polyadenylated and further reverse transcribed into cDNA using miRNA First-Strand cDNA Synthesis and qRT-PCR kits (Invitrogen). Next, we diluted the cDNA 1:10 in DEPC-treated water and the diluent cDNA served as the template for qPCR.

We used Applied Biosystems 7500 detection system to perform the qPCR. U6 snRNA was used as an endogenous control for normalization. The forward primers of hsa-miR-34c-5p and U6 used in our study were synthesized by Invitrogen. The primer sequence of hsa-miR-34c-5p was 5'-AGGCAGTGTAGTTAGCTGATTGC-3' and the primer sequence of U6 was 5'-CGCAAGGATGACACGCAAA TTC-3'. The universal reverse primer was offered in the kit. After mixing $10 \mu \mathrm{l}$ of the PCR system, which included $5 \mu \mathrm{l}$ of SYBR-Green Master Mix (Toyobo, Japan), $1 \mu l$ of the specific forward primer $(1 \mu \mathrm{mol} / \mathrm{l})$, and $1 \mu \mathrm{l}$ of the reverse primer ( $1 \mu \mathrm{mol} / \mathrm{l}), 1 \mu \mathrm{l}$ plus solution, $1 \mu \mathrm{l}$ template and $1 \mu \mathrm{l}$ DEPCtreated water, we placed the reactions in a real-time instrument at $95^{\circ} \mathrm{C}$ for $3 \mathrm{~min}$, and 40 cycles $\left(95^{\circ} \mathrm{C}, 15 \mathrm{sec}\right.$ and $60^{\circ} \mathrm{C}, 1 \mathrm{~min}$ for each cycle). Then, we obtained $\mathrm{Ct}$ values for each sample, and the relative expression of miR-34c was calculated by the $2^{-\Delta \Delta \mathrm{Ct}}$ method.

Cell proliferation assay. Cells were transfected $24 \mathrm{~h}$ after seeding in 96 -well plates at 2,500 cells/well. Then we evaluated cell proliferation using CCK-8 reagent (Beyotime Institute of Biotechnology, China) at 24, 48, 72, and $96 \mathrm{~h}$ after transfection, respectively. Briefly, we replaced the DMEM in the well, then added $10 \mu 1$ of CCK- 8 solution into each well and incubation was carried out at $37^{\circ} \mathrm{C}$ for an additional $2 \mathrm{~h}$. We then determined the absorbance at a wavelength of $450 \mathrm{~nm}$.

Colony formation assay. Seventy-two hours after transfection, the cells were collected and resuspended in DMEM with $10 \%$ FBS. Then the cells were seeded in 6-well plates at an amount of 800 cells/well, and incubated at $37^{\circ} \mathrm{C}$ in a humidified incubator with $5 \% \mathrm{CO}_{2}$ for 14 days until visible colonies (containing 40 or more cells) formed. The cell colonies were stained with crystal violet for $30 \mathrm{~min}$. We counted the numbers of colonies in each group.

Cell apoptosis assay. The cell apoptosis assay was performed using the Alexa Fluor 488 Annexin V apoptosis kit (Invitrogen). Briefly, the cells were collected $72 \mathrm{~h}$ after transfection, washed twice with cold PBS and resuspended in Annexin-binding buffer supplied in the kit. Subsequently, the cells were stained using Annexin V and PI according to the manufacturer's instructions. Cell apoptosis was analyzed by flow cytometry.

Cell cycle assay. Approximately $2 \times 10^{5}-1 \times 10^{6}$ cells were collected $48 \mathrm{~h}$ after transfection, and washed once with PBS. Then the cells were resuspended in $1 \mathrm{ml}$ DNA staining solution (MultiSciences Biotech Co., Ltd.), incubated for $30 \mathrm{~min}$ at room temperature and analyzed by flow cytometry in the presence of the dye.

Transwell migration and invasion assays. For the Transwell migration assay, the cells were harvested $72 \mathrm{~h}$ after transfection and resuspended in serum-free medium at a concentration of $1.5 \times 10^{5}$ cells $/ \mathrm{ml}$. Two hundred microliters of the cell suspension was transferred into the top chamber with a non-coated membrane (8- $\mu \mathrm{m}$ pore; BD Biosciences), and the chamber was inserted in a 24-well plate. For the Transwell invasion assay, $200 \mu 1$ of the cell suspension at a concentration of $3.0 \times 10^{5}$ cells $/ \mathrm{ml}$ was transferred into the top chamber with a Matrigel-coated membrane (8- $\mu \mathrm{m}$ pore; BD Biosciences). In both assays, $500 \mu 1$ DMEM containing 10\% FBS was added to the bottom chamber in a 24-well plate. The plate was placed in an incubator for $24 \mathrm{~h}$. After that, we wiped away the cells on the upper surface of the membrane with a cotton swab, then fixed the cells on the lower surface of the membrane in $4 \%$ paraformaldehyde for $30 \mathrm{~min}$, stained them with crystal violet for $30 \mathrm{~min}$, and evaluated the migration or invasive ability by counting the numbers of stained cells under a microscope.

Western blot analysis. Total proteins in each group of cells were extracted $72 \mathrm{~h}$ after transfection, and resolved by $10 \%$ SDS-PAGE. The proteins were transferred onto PVDF membranes (Solarbio) and blocked in TBST containing 5\% skim milk for $1 \mathrm{~h}$. Next, the membranes were incubated with primary antibodies for E2F3 (rabbit anti-human polyclonal antibody, diluted as 1:1,000, ab50917; Abcam) and $\beta$-actin (1:10,000, AP0060; BioWorld) for $1 \mathrm{~h}$, respectively. After washing 3 times with TBST (each time $15 \mathrm{~min}$ ), the membranes were incubated with secondary antibody (peroxidase conjugated goat anti-rabbit IgG, 1:5,000, GAR007; MultiSciences Biotech Co., Ltd.) for $1 \mathrm{~h}$. After washing the membranes 3 times with TBST (each time $15 \mathrm{~min}$ ), we detected the blots using SuperSignal West Femto Maximum Sensitivity Substrate kit (Thermo Fisher Scientific) and protein bands were exposed to Kodak film (Sigma-Aldrich). Relative expression of E2F3 protein was normalized to $\beta$-actin.

Statistical analysis. Statistical analysis of all data was performed using SPSS 19.0 software package. Each experiment was performed at least 3 times, and differences between each group were evaluated by one-way ANOVA. The results 


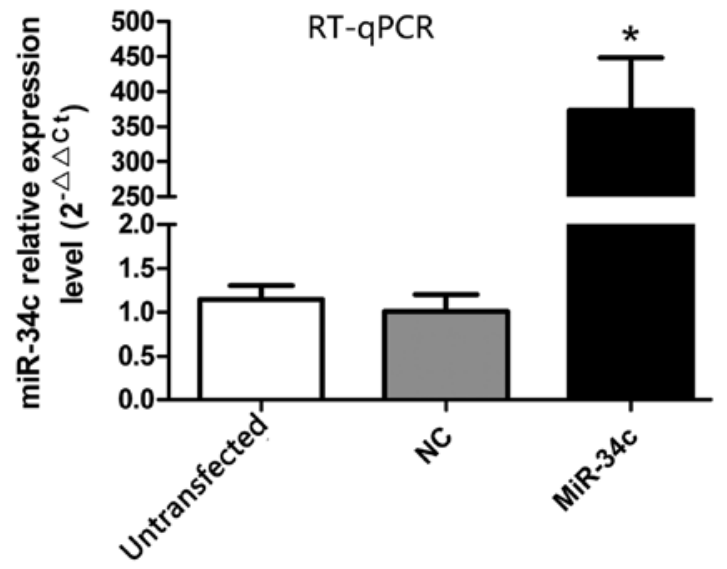

Figure 1. Expression levels of miR-34c as detected by RT-qPCR $48 \mathrm{~h}$ after transfection. Bars show the mean \pm SD of triplicate experiments, ${ }^{*} \mathrm{P}<0.01$.

are shown as the mean $\pm \mathrm{SD}$. $\mathrm{P}<0.05$ was considered to indicate a statistically significant result.

\section{Results}

Expression of miR-34c after transfection. The expression of miR-34c was detected by RT-qPCR 48 h after transfection (Fig. 1). There was increased expression of $\mathrm{miR}-34 \mathrm{c}$ in the miR-34c group compared with the NC and untransfected group (miR-34c group, 373.43 \pm 74.95 ; NC group, 1.01 \pm 0.19 ; untransfected group, $1.14 \pm 0.16, \mathrm{P}<0.01)$.

miR-34c inhibits the growth of HEC-1-B cells. To confirm a proliferation-suppressive effect of $\mathrm{miR}-34 \mathrm{c}$ in the HEC-1-B cells, the absorbance at the wavelength of $450 \mathrm{~nm}$ was measured $2 \mathrm{~h}$ after adding CCK- 8 to reflect the amount of cells indi- rectly. The absorbance in the miR-34c group was significantly decreased by $28.0 \%(\mathrm{P}<0.01)$ at $72 \mathrm{~h}$ and $54.1 \%(\mathrm{P}<0.01)$ at $96 \mathrm{~h}$ compared with the NC and untransfected group (Fig. 2A), indicating that the cell proliferation was suppressed followed by increased expression of $\mathrm{miR}-34 \mathrm{c}$.

To further prove the function of miR-34c on growth inhibition of the HEC-1-B cells, we examined the role of miR-34c on cell colony formation. As shown in Fig. 2B, the colony formation capacity was markedly decreased in the miR-34c group. We counted the numbers of colonies in each group, and the numbers of colonies in the NC and untransfected group reached $149.7 \pm 4.0$ and $143.0 \pm 2.6$, respectively, while it was only $49.0 \pm 2.5$ in the miR-34c group $(\mathrm{P}<0.01)$.

miR-34c promotes the apoptosis of HEC-1-B cells. Seventy-two hours after transfection, the cells in the miR-34c group were in an obviously poorer status when compared to the NC and untransfected group (Fig. 3A). Following analysis by flow cytometry (Fig. 3B), the percentages of early and late apoptotic cells were significantly increased in the miR-34c group (16.76\% in total) when compared with these percentages in the other 2 groups (4.32 and 5.33\% in total, respectively).

miR-34c induces cell cycle arrest. Cell cycle distribution was evaluated by flow cytometry. Overexpression of miR-34c led to the accumulation of cells in the $G_{1}$ phase and the reduction of cells in the $S$ and $G_{2}$ phase (Fig. 4). These results suggest that miR-34c influenced cell cycle transition from $G_{1}$ to the $S$ phase and induced cell cycle arrest at the $G_{1}$ phase.

miR-34c inhibits the migration and invasion of HEC-1-B cells. We identified the effect of miR-34c on the migration (Fig. 5A) and invasion (Fig. 5C) of the HEC-1-B cells by Transwell assay. In the Transwell migration assay, a $70.5 \%$
A

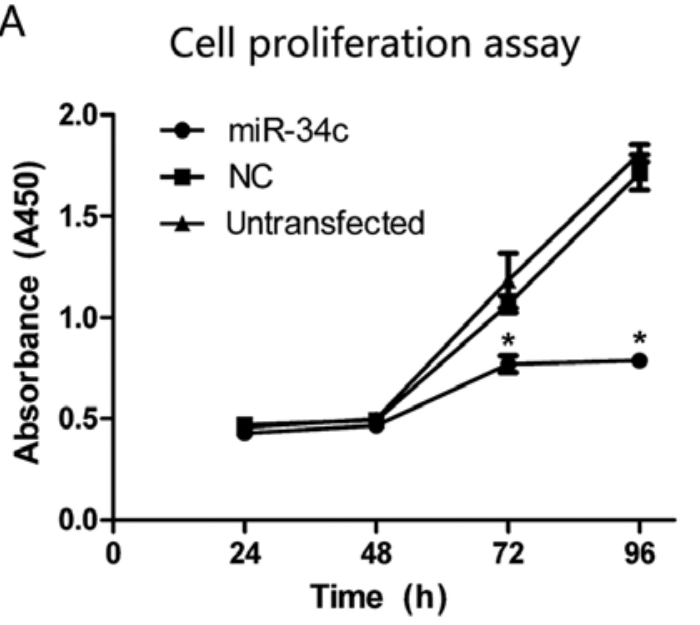

B

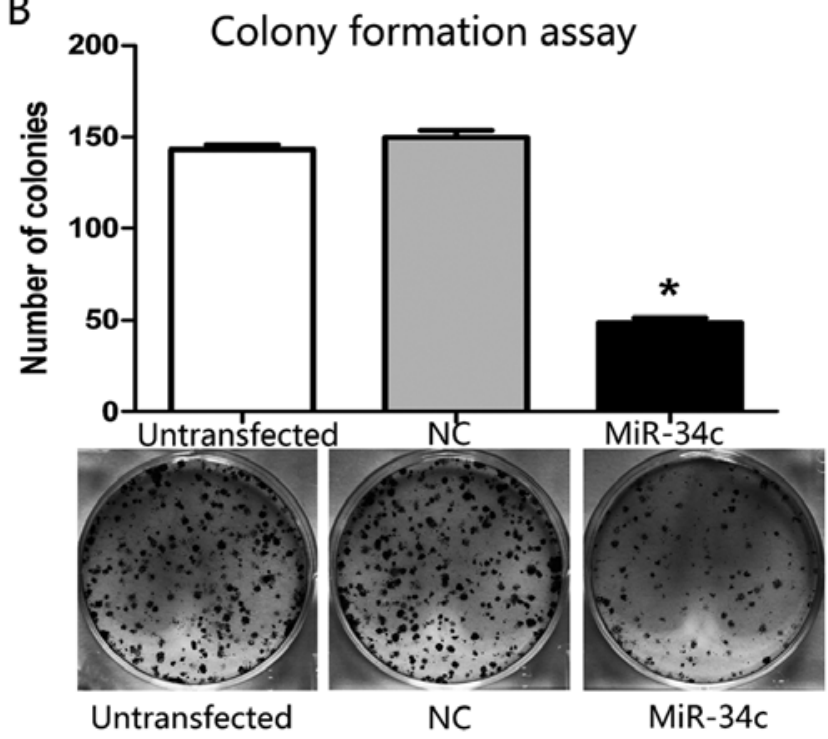

Figure 2. (A) The amounts of active cells in each group were assessed at the indicated times after transfection by CCK- 8 assay. The data represent the mean \pm SD of triplicate experiments, ${ }^{*} \mathrm{P}<0.01$. (B) Colony formation assay. The numbers of colonies are presented as the mean \pm SD (bars) of three separate experiments, ${ }^{*} \mathrm{P}<0.01$. 


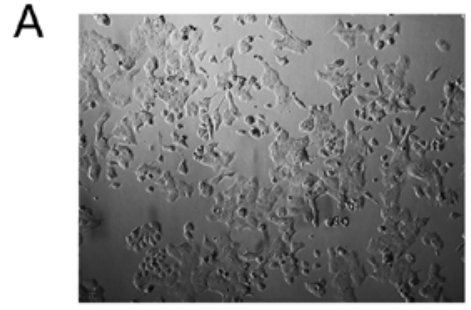

Untransfected

B Cell apoptosis assay

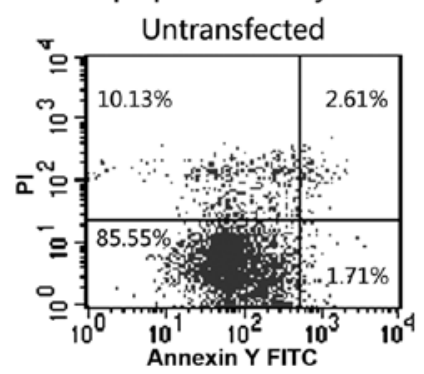

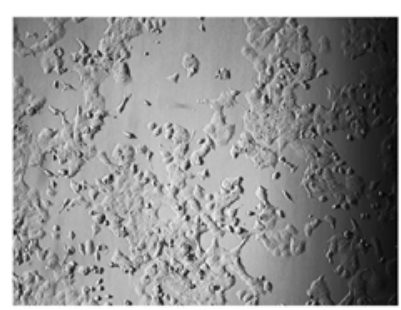

NC

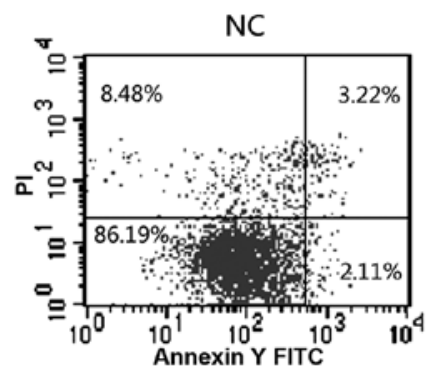

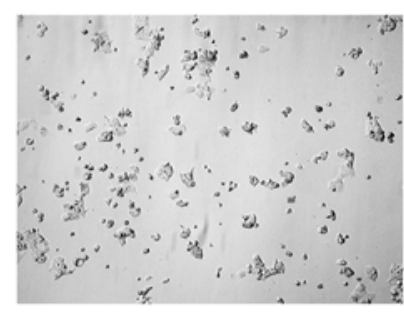

$\mathrm{MiR}-34 \mathrm{c}$

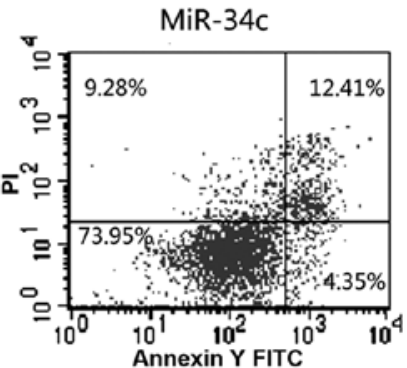

Figure 3. (A) State of the cells in each group observed under a microscope $72 \mathrm{~h}$ after transfection. (B) Cell apoptosis assay. Cell apoptosis was detected by flow cytometry. In each plot, the right lower quadrant represents early apoptotic cells, and the right upper quadrant represents late apoptotic cells. The assay was repeated 3 times and similar results were observed.

\section{Cell cycle assay}

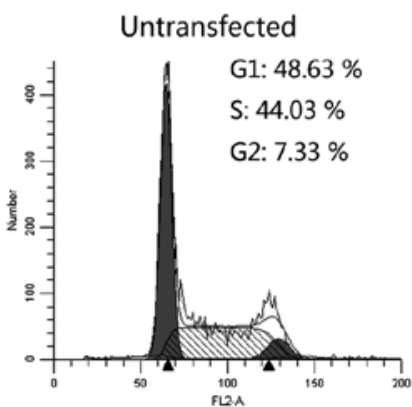

NC

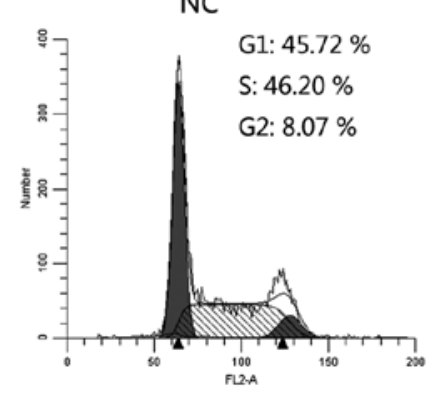

MiR-34c

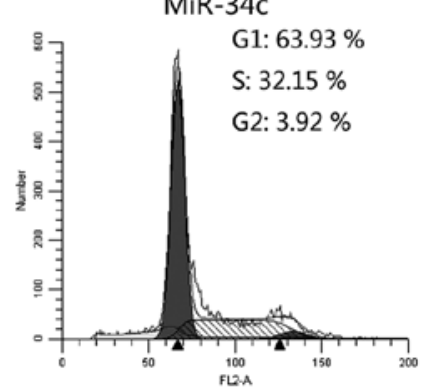

Figure 4. Cell cycle assay. The data show the percentage of each phase of cell cycle arrest in each group. This experiment was repeated 3 times and similar results were observed.

decrease in HEC-1-B cells $(\mathrm{P}<0.01)$ was detected $72 \mathrm{~h}$ after transfection of the hsa-miR-34c-5p mimics (Fig. 5B). In the Transwell invasion assay, a 75.8\% decrease in HEC-1-B cells was noted after transfection of the hsa-miR-34c-5p mimics $(\mathrm{P}<0.01$, Fig. 5D).

miR-34c suppresses the expression of E2F3 protein. To determine whether miR-34c regulates the expression of E2F3 protein, the expression of E2F3 was detected by western blot analysis $72 \mathrm{~h}$ after transfection. As expected, the expression of E2F3 protein was apparently inhibited after the transfection of the hsa-miR-34c-5p mimics (Fig. 6A and B).

\section{Discussion}

Our research together with a study conducted by Hiroki et al (15) showed that miR-34c is downregulated in EC, and this transformation may be an important factor in the poor prognosis of EC. To further study the function of miR-34c, we upregulated the expression of miR-34c in HEC-1-B cells by transfection with the hsa-miR-34c-5p mimics, and we found that the overexpression of miR-34c inhibited cell proliferation, colony formation, migration and invasion, promoted apoptosis, and induced cell cycle arrest, demonstrating that miR-34c is a suppressor of HEC-1-B cells, and western blot analysis demonstrated that E2F3 protein may be a target of miR-34c. To our knowledge, the present study is the first to confirm that miR-34c suppresses HEC-1-B cells by targeting E2F3.

In the present study, we found that the decrease in the number of cells may be partly related to cell apoptosis. Inhibition of cell proliferation together with apoptosis ultimately inhibited the formation of cell colonies. A previous study showed that inhibition of cell proliferation and apoptosis may be partly caused by cell cycle arrest after transfection with miR-34s (19). Notably, our results found that both inhibition of cell proliferation and apoptosis appeared $72 \mathrm{~h}$ after transfection with the hsa-miR-34c-5p mimics, later than cell cycle arrest ( $48 \mathrm{~h}$ after transfection). Cell cycle arrest at the $\mathrm{G}_{1}$ phase is likely to be the key function of miR-34c in HEC-1-B cells. We also found that miR-34c significantly inhibited the 
A

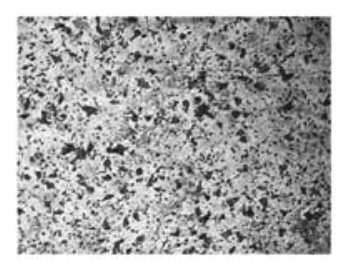

Untransfected

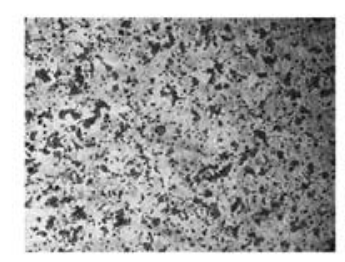

NC

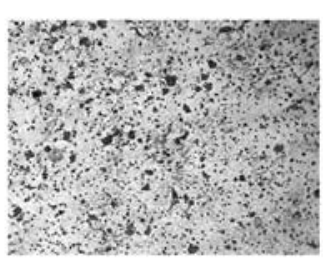

MiR-34c

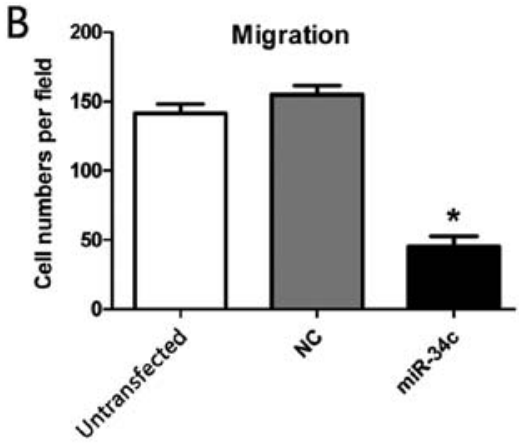

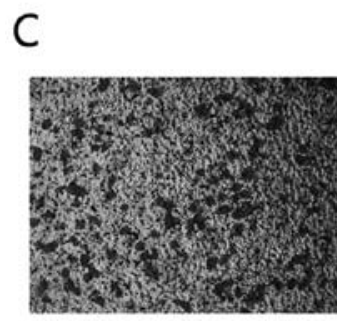

Untransfected

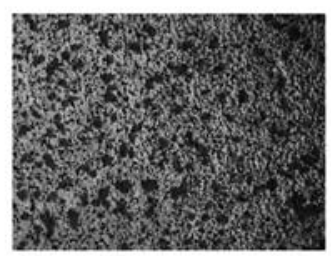

NC

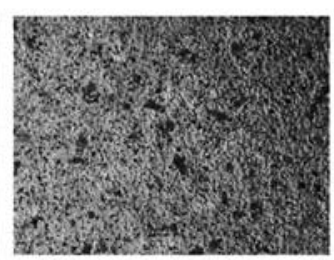

MiR-34c

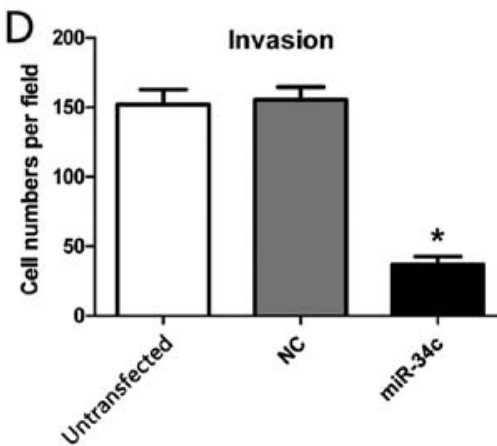

Figure 5. (A) Migration assay observed under a microscope. (B) Bars show the cell numbers in each group after staining in the migration assay. The data represent the mean \pm SD of triplicate experiments, ${ }^{*} \mathrm{P}<0.01$. (C) Invasion assay observed under a microscope. (D) Bars show the cell numbers in each group in the invasion assay. The data represent the mean $\pm \mathrm{SD}$ of triplicate experiments, ${ }^{\prime} \mathrm{P}<0.01$.

A

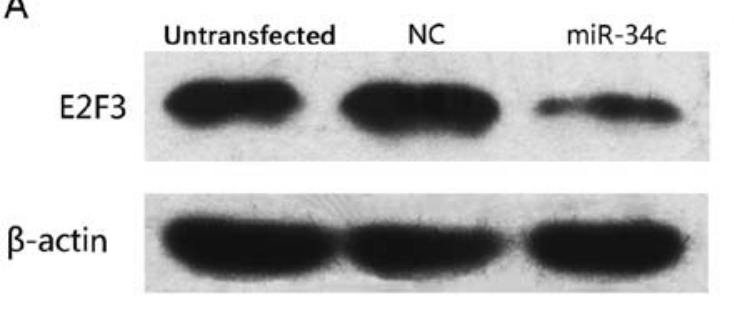

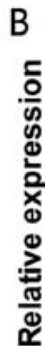

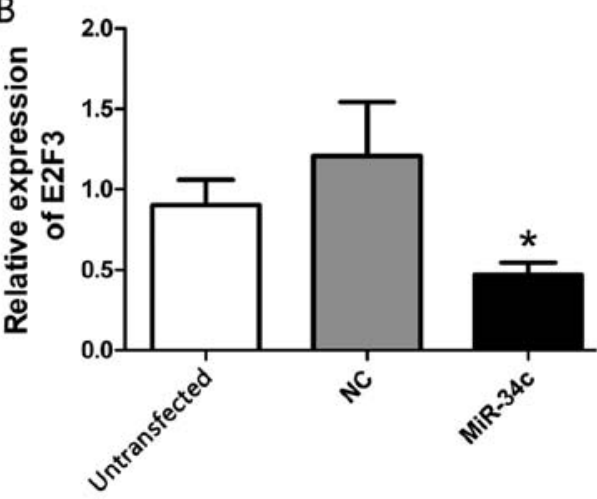

Figure 6. (A) The levels of E2F3 and $\beta$-actin proteins detected in the HCE-1-B cells $72 \mathrm{~h}$ after transfection by western blot analysis. (B) Bars show the expression levels of E2F3 relative to $\beta$-actin. The expression of E2F3 in the miR-34c group was significantly inhibited. Mean \pm SD of triplicate experiments, ${ }^{*} \mathrm{P}<0.05$.

migration and invasion of the HEC-1-B cells, which may also be clinically significant.

TargetScan analysis indicates that E2F3 may be a target of miR-34c. E2F3 is a member of the E2F family, whose potential oncogenic capacity was reported (20), and studies show that E2F3 regulates E2F-mediated DNA replication and cell proliferation by a p53-dependent negative feedback loop (21). Lax et al (22) reported that p53 mutations were found in $93 \%$ of uterine serous carcinoma and $17 \%$ of uterine endometrioid carcinoma, and that this may be responsible for their morphology and biologic behavior. In addition, it has been demonstrated that members of the miR-34 family are direct transcriptional targets of p53, playing a role as tumor suppressors $(19,23)$. Based on the reports mentioned above, we proposed that the effects of miR-34c on HEC-1-B cells operate through E2F3 protein. To test this hypothesis, we used western blot analysis to demonstrate that $\mathrm{E} 2 \mathrm{~F} 3$ was markedly downregulated after transfection with the hsa-miR-34c-5p mimics. These studies, as well as our results, suggest that $\mathrm{E} 2 \mathrm{~F} 3$ protein is a target protein of miR-34c. It has been reported that overexpression of E2F3 protein is an important marker for poor clinical outcome in prostate cancer (24). These results suggest that E2F3 may exert a significant influence on tumor progression.

Leone et al (25) demonstrated that E2F3 influences cell cycle arrest in the induction of $\mathrm{S}$ phase during the transition from quiescence to proliferation by regulating Cdc6, cyclin E, $\mathrm{Cdk} 2$ and $\mathrm{Mcm}$ proteins. Similarly, our data showed reduced E2F3, and cell cycle arrest at $\mathrm{G}_{1}$ phase accompanied by reduction in the percentage of cells in the $\mathrm{S}$ phase after transfection of hsa-miR-34c-5p mimics, suggesting that miR-34c acts as a 
tumor suppressor by inducing cell cycle arrest at the $G_{1}$ phase via E2F3.

Invasive growth in many human tumors is associated with overexpression of MET (26), and recent studies show that knockdown of cyclophilin A leads to a significant inhibition of cell migration and invasion in HEC-1-B cells by downregulating focal adhesion signaling (27). Our data revealed that miR-34c significantly inhibited migration and invasion of HEC-1-B cells; however, futher studies are necessary to confirm the effects of miR-34c on the migration and invasion of HEC-1-B cells and whether this is also associated with MET and cyclophilin A.

In conclusion, miR-34c acts as a direct target of p53, its overexpression suppresses the expression of E2F3 protein, and a low level of E2F3 causes cell cycle arrest at the $G_{1}$ phase by acting on a series of cell cycle arrest-related proteins. Then, cell cycle arrest induces cell proliferation inhibition and apoptosis partly and further inhibits cell colony formation. miR-34c can also inhibit cell migration and invasion.

Although therapeutic strategies for EC have improved greatly in the last few decades, EC still has a significantly poor prognosis. Understanding the pathogenesis at the molecular level is essential for the development of new targeted therapies. In the present study, we successfully identified miR-34c as a suppressor of the EC cell line (HEC-1-B), and demonstrated E2F3 as a target of miR-34c in HEC-1-B cells. Further studies to ascertain whether overexpression of miR-34c has a therapeutic role in EC are necessary. We believe that miR-34c has potential value in the early diagnosis and molecular therapy of EC.

\section{Acknowledgements}

This study was supported by the Zhejiang Provincial Natural Science Foundation of China (no. Y2090699).

\section{References}

1. Ueda SM, Kapp DS, Cheung MK, Shin JY, Osann K, Husain A, Teng NN, Berek JS and Chan JK: Trends in demographic and clinical characteristics in women diagnosed with corpus cancer and their potential impact on the increasing number of deaths. Am J Obstet Gynecol 198: 218.e1-218.e6, 2008.

2. Bartel DP: MicroRNAs: genomics, biogenesis, mechanism, and function. Cell 116: 281-297, 2004.

3. Takamizawa J, Konishi H, Yanagisawa K, Tomida S, Osada H, Endoh H, Harano T, Yatabe Y, Nagino M, Nimura Y, et al: Reduced expression of the let-7 microRNAs in human lung cancers in association with shortened postoperative survival. Cancer Res 64: 3753-3756, 2004.

4. Bou Kheir T, Futoma-Kazmierczak E, Jacobsen A, Krogh A, Bardram L, Hother C, Grønbæk K, Federspiel B, Lund AH and Friis-Hansen L: miR-449 inhibits cell proliferation and is down-regulated in gastric cancer. Mol Cancer 10: 29, 2011.

5. Esquela-Kerscher A and Slack FJ: Oncomirs - microRNAs with a role in cancer. Nat Rev Cancer 6: 259-269, 2006.

6. Jiang F, Liu T, He Y, Yan Q, Chen X, Wang H and Wan X: MiR-125b promotes proliferation and migration of type II endometrial carcinoma cells through targeting TP53INP1 tumor suppressor in vitro and in vivo. BMC Cancer 11: 425, 2011.

7. Tsuruta T, Kozaki K, Uesugi A, Furuta M, Hirasawa A, Imoto I, Susumu N, Aoki D and Inazawa J: miR-152 is a tumor suppressor microRNA that is silenced by DNA hypermethylation in endometrial cancer. Cancer Res 71: 6450-6462, 2011.

8. Le XF, Merchant O, Bast RC and Calin GA: The roles of microRNAs in the cancer invasion-metastasis cascade. Cancer Microenviron 3 : 137-147, 2010.
9. Ye W, Xue J, Zhang Q, Li F, Zhang W, Chen H, Huang Y and Zheng F: miR-449a functions as a tumor suppressor in endometrial cancer by targeting CDC25A. Oncol Rep 32: 1193-1199, 2014.

10. Wong MY, Yu Y, Walsh WR and Yang JL: microRNA-34 family and treatment of cancers with mutant or wild-type p53 (Review). Int J Oncol 38: 1189-1195, 2011.

11. Son MS, Jang MJ, Jeon YJ, Kim WH, Kwon CI, Ko KH, Park PW, Hong SP, Rim KS, Kwon SW, et al: Promoter polymorphisms of pri-miR-34b/c are associated with hepatocellular carcinoma. Gene 524: 156-160, 2013.

12. Roy S, Levi E, Majumdar AP and Sarkar FH: Expression of miR-34 is lost in colon cancer which can be re-expressed by a novel agent CDF. J Hematol Oncol 5: 58, 2012.

13. Oeggerli M, Tomovska S, Schraml P, Calvano-Forte D, Schafroth S, Simon R, Gasser T, Mihatsch MJ and Sauter G: E2F3 amplification and overexpression is associated with invasive tumor growth and rapid tumor cell proliferation in urinary bladder cancer. Oncogene 23: 5616-5623, 2004.

14. Ziebold U, Reza T, Caron A and Lees JA: E2F3 contributes both to the inappropriate proliferation and to the apoptosis arising in Rb mutant embryos. Genes Dev 15: 386-391, 2001.

15. Hiroki E, Suzuki F, Akahira J, Nagase S, Ito K, Sugawara J, Miki Y, Suzuki T, Sasano H and Yaegashi N: MicroRNA-34b functions as a potential tumor suppressor in endometrial serous adenocarcinoma. Int J Cancer 131: E395-E404, 2012.

16. Jiang L, Meng W, Zeng J, Hu H and Lu L: MiR-34c oligonucleotide enhances chemosensitivity of Ishikawa cell to cisplatin by inducing apoptosis. Cell Biol Int 37: 577-583, 2013.

17. Kubo T, Toyooka S, Tsukuda K, Sakaguchi M, Fukazawa T, Soh J, Asano H, Ueno T, Muraoka T, Yamamoto H, et al: Epigenetic silencing of microRNA-34b/c plays an important role in the pathogenesis of malignant pleural mesothelioma. Clin Cancer Res 17: 4965-4974, 2011.

18. Toyota M,Suzuki H, Sasaki Y, Maruyama R, Imai K, Shinomura Y and Tokino T: Epigenetic silencing of microRNA-34b/c and B-cell translocation gene 4 is associated with $\mathrm{CpG}$ island methylation in colorectal cancer. Cancer Res 68: 4123-4132, 2008.

19. He L, He X, Lim LP, de Stanchina E, Xuan Z, Liang Y, Xue W, Zender L, Magnus J, Ridzon D, et al: A microRNA component of the p53 tumour suppressor network. Nature 447: 1130-1134, 2007.

20. Chen HZ, Tsai SY and Leone G: Emerging roles of E2Fs in cancer: an exit from cell cycle control. Nat Rev Cancer 9: 785-797, 2009.

21. Timmers C, Sharma N, Opavsky R, Maiti B, Wu L, Wu J, Orringer D, Trikha P, Saavedra HI and Leone G: E2f1, E2f2, and E2f3 control E2F target expression and cellular proliferation via a p53-dependent negative feedback loop. Mol Cell Biol 27: 65-78, 2007.

22. Lax SF, Kendall B, Tashiro H, Slebos RJ and Hedrick L: The frequency of p53, K-ras mutations, and microsatellite instability differs in uterine endometrioid and serous carcinoma: evidence of distinct molecular genetic pathways. Cancer 88: 814-824, 2000.

23. Corney DC, Flesken-Nikitin A, Godwin AK, Wang W and Nikitin AY: MicroRNA-34b and microRNA-34c are targets of p53 and cooperate in control of cell proliferation and adhesion-independent growth. Cancer Res 67: 8433-8438, 2007.

24. Foster CS, Falconer A, Dodson AR, Norman AR, Dennis N, Fletcher A, Southgate C, Dowe A, Dearnaley D, Jhavar S, et al: Transcription factor E2F3 overexpressed in prostate cancer independently predicts clinical outcome. Oncogene 23: 58715879, 2004.

25. Leone G, DeGregori J, Yan Z, Jakoi L, Ishida S, Williams RS and Nevins JR: E2F3 activity is regulated during the cell cycle and is required for the induction of S phase. Genes Dev 12: 2120-2130, 1998.

26. Migliore C, Petrelli A, Ghiso E, Corso S, Capparuccia L, Eramo A, Comoglio PM and Giordano S: MicroRNAs impair MET-mediated invasive growth. Cancer Res 68: 10128-10136, 2008.

27. Li Z, Gou J and Xu J: Down-regulation of focal adhesion signaling in response to cyclophilin A knockdown in human endometrial cancer cells, implicated by cDNA microarray analysis. Gynecol Oncol 131: 191-197, 2013. 